\title{
El Castillo: territorio, sociedad y subjetividades de la espera
}

\begin{abstract}
Ana María Álvarez. Universidad Católica Silva Henríquez, Santiago, Chile. Héctor Cavieres. Universidad Católica Silva Henríquez, Santiago, Chile.
\end{abstract}

RESUMEN | En 2013 se realizó una investigación cualitativa en El Castillo, comuna de La Pintana, Santiago, Chile, que tuvo como referente los conceptos de "espera" y de "territorios de la espera". La Pintana fue creada en 1981 en el marco de las reformas urbanas neoliberales de la dictadura, con el fin de acoger población erradicada. Se entiende la espera como una situación generada a partir de desplazamientos de población que se instala (o es instalada) a vivir en un territorio deficitario que no mejora, así como tampoco mejora la condición socioeconómica de sus habitantes. Se concluye que El Castillo es un territorio y una sociedad de la espera. Esta condición define el lugar, la identidad y las prácticas espaciales de sus habitantes. Sin embargo, la forma y contenido de la espera varía según generaciones: en los jóvenes, una espera esperanzada; y en los adultos y viejos, una espera resignada y nostálgica.

PALABRAS ClAVE | pobreza, política habitacional, fragmentación urbana.

ABSTRACT | During 2013, a qualitative research was conducted in the region of El Castillo, district of La Pintana, Santiago, Chile. This study was conceptually framed by the notions of "waiting" and "waiting territories". The district of La Pintana was created in 1981 within the framework of urban reforms of the military dictatorship, in order to relocate displaced groups. "Waiting" is understood as a temporary situation that occurs when the displaced population is settled in a territory lacking in resources, without improvement over time, and where the socio-economic status of those living in it does not improve either. It follows as a conclusion that El Castillo is a waiting territory and a waiting society. This condition defines the place, the social identity and the spatial practices of its inhabitants. The form and content of waiting changes depending on the generation: for the youth, "waiting" is accompanied by hope and for adults and old people, "waiting" is a rather resigned or nostalgic conception.

KEYWORDS | poverty, housing policy, urban fragmentation.

Recibido el 18 de julio de 2014, aprobado el 16 de febrero de 2015

E-mail: Ana María Álvarez, amalvare@ucsh.cl | Héctor Cavieres, hcavieres@ucsh.cl 
No hay medio más eficaz para desarrollar en el pueblo el espiritu conservador, para hacerlo partidario y defensor del orden y la estabilidad social, que hacerlo propietario. Se ha probado que no hay trabajador más laborioso, más asiduo y ordenado que el propietario; nunca se le ha visto en desórdenes y revueltas. E. Aragón, Las habitaciones para obreros (1900), p. 75.

\section{Antecedentes}

Vidal, Musset y Vidal (2011) reconocen los fenómenos de movilidad y desplazamiento como características significativas de nuestras sociedades contemporáneas. Sin embargo, lejos de tratarse de procesos fluidos, homogéneos o lineales -señalan los autores-, estos desplazamientos están puntuados por tiempos de espera y poseen una traducción espacial, más allá de las razones que indujeron su surgimiento y moldean los lugares donde esta espera se instala (cfr. Vidal \& Musset, 2011). La traducción espacial de la espera configura territorios que acogen "sociedades en espera”; estos territorios adoptan múltiples formas, adquieren diferentes dimensiones y estatus jurídicos, se articulan de distinta manera con el entorno en el cual se insertan, a la vez que se despliegan en ellos diversas dinámicas económicas y sociales (Vidal \& Musset 2015a). En este contexto, los "territorios de la espera" pueden ser considerados como espacios destinados, voluntaria o involuntariamente, a que poblaciones desplazadas o en proceso de desplazamiento se dispongan a esperar (Vidal, Musset \& Vidal, 2011). Esta definición hace plausible asumir los sectores de la ciudad donde se asienta población pobre como territorios de la espera, uno, porque dichos territorios se han constituido, en su mayoría, como resultado de desplazamientos internos forzados y/o voluntarios (Espinoza, 1988; Garcés, 2002); y dos, porque en el caso de los pobres de la ciudad de Santiago, a pesar de haber obtenido en los últimos 35 ańos viviendas sólidas y propias por la vía del subsidio habitacional, las condiciones del hábitat urbano y de los territorios que habitan continúan siendo deficitarias, al igual que son restringidas sus posibilidades de movilidad social y residencial (Ducci, 1997; Rodríguez, Sugranyes \& Tironi, 2005).

Los territorios de la espera nacen de la movilidad y en la movilidad (Vidal et al., 2011). Ejemplo de ello es la Población El Castillo, constituida como caso de estudio para esta investigación. Las erradicaciones que tuvieron lugar en Chile en la década de los ochenta y que dieron origen a este conjunto son un ejemplo de movilidad forzada. La comuna de La Pintana, situada en la zona sur del Área Metropolitana de Santiago y donde se localiza El Castillo, fue creada el año 1981 por un decreto con fuerza de ley de la dictadura militar (DFL 1-3260), en el contexto de formación de nuevas comunas destinadas a acoger población erradicada de distintas zonas de la ciudad. En el caso específico de las comunas del área sur, estas fueron receptoras del 53\% del total de erradicados provenientes de otras comunas, con La Pintana como "el lugar de destino de la mayoría de las familias erradicadas a dicha zona" (Morales \& Rojas, 1986, p. 37). La población de las nuevas comunas se reconfiguró a partir de quienes vivían en campamentos de radicación o nuevos campamentos, 
y de población residente en poblaciones de erradicación trasladada desde su propia comuna o de otra. La Pintana fue no solo la comuna que recibió los mayores contingentes de población erradicada, sino también la que mostraba la tasa más alta de población erradicada de campamentos y que residía en poblaciones de erradicación (Morales \& Rojas, 1986). Gurovich (1990) señala que, en comparaciones relativas a distintos indicadores sociales y urbanos realizadas a principios de los ochenta y fines de los noventa entre diferentes comunas del Gran Santiago, La Pintana muestra, en diferentes momentos de medición, los resultados más deficitarios en relación con el conjunto de indicadores examinados.

En 1987, los habitantes de La Pintana muestran el mayor grado de insatisfacción de sus necesidades básicas, en una comparación de ocho comunas que utilizan variables de salud, nutrición, vivienda y educación (...). Presentaba además un déficit considerable de servicios de atención a la comunidad en distintas áreas (...). A nivel de gestión local, sólo después de seis años el nuevo Municipio pudo considerar que cumplía con la dotación de equipamiento básico. Por otra parte, a las carencias materiales de la comuna se sumó la sensación de desarraigo manifestada por las familias erradicadas. (Gurovich, 1990, p. 9)

Como se señala en el Plan de Desarrollo Comunal (PLADECo) para el periodo 20122016 (I. Municipalidad de La Pintana, 2012), ello se explica en parte por la historia misma de La Pintana:

Fue constituida en comuna urbana con una escasa población, con alrededor del $80 \%$ de su territorio sin urbanizar, sin comercio ni servicios, y sin actividades productivas salvo aquellas propias de las zonas rurales. Debido al efecto combinado de las radicaciones forzosas que aplicó el gobierno de la época durante la primera parte de los ańos ochenta, y al valor extraordinariamente bajo del suelo comunal, que hacían particularmente rentables los proyectos de vivienda social básica o casetas sanitarias, la comuna más que duplicó su población original en un lapso de 10 años, produciéndose una extrema concentración de pobreza urbana acompañada de carencias igualmente extremas en materia de infraestructura, equipamientos, servicios y actividades generadoras de empleo en general. (p. 6)

Hasta el día de hoy, la comuna no ha sido capaz de generar una base económica para producir empleos, y en sus más de treinta ańos de existencia tampoco ha podido atraer la inversión inmobiliaria necesaria para dotar de mixtura sociocultural al espacio. Cabe señalar que más del $90 \%$ de las viviendas allí instaladas son viviendas sociales y que sigue siendo, desde su fundación, una de las comunas más pobres del país (I. Municipalidad de La Pintana, 2012).

\section{La propuesta de investigación}

El conjunto de antecedentes proporcionados por estudios efectuados en distintos momentos de la evolución de la comuna (Gurovich, 1990; Rodríguez \& Icaza, 1993) y por el pladeco 2012-2016 (I. Municipalidad de La Pintana, 2012), nos permitieron formular el supuesto de que en La Pintana, territorio y habitantes vivirían una 
suerte de "moratoria social y espacial". El lugar estaría en un tránsito permanente hacia un estado "distinto" que no se termina nunca de adquirir. El espacio no es lo que "debería ser" y no dejará nunca de "ser lo que es", tanto en términos materiales como simbólicos. Esta interpretación nos permitió concebir, a priori, El Castillo como territorio de la espera, en la medida en que esta condición implica una expectativa insatisfecha en relación con el lugar donde se habita (Álvarez \& Sánchez, 2015). Ello implica ser un territorio de tránsito hacia otro mejor, cuestión que supone para el residente una relación particular con el espacio. Lo anterior dio lugar a las siguientes preguntas de investigación: si El Castillo es considerado, a priori, como un territorio de la espera, ¿cuáles son sus características específicas en tal sentido? ¿Existen diferencias en los contenidos de la espera en distintas generaciones de residentes? Al respecto, hicimos una distinción entre los que han vivido en el territorio desde su fundación hasta el momento presente -quienes eran niños durante las erradicaciones y han hecho su vida en el lugar- y quienes son ahora jóvenes, principales portadores del estigma territorial y "responsables", ante la propia comunidad y la sociedad, de los problemas de violencia y narcotráfico que vive la población (Cornejo, 2012). Los objetivos propuestos fueron, en consecuencia, caracterizar a El Castillo como territorio y sociedad de la espera, analizando su surgimiento y evolución desde un punto de vista histórico, e identificar, a partir de un criterio generacional, similitudes y diferencias entre sus residentes en la vivencia de la espera. El estudio tuvo un carácter exploratorio y la muestra fue intencionada y voluntaria.

\section{El Castillo: creación y transformación como territorio de la espera}

Según el Censo 2002, El Castillo poseía a la fecha 37.985 habitantes, correspondientes al 20\% de la población comunal (191.743 habitantes). De ellos, en un $50,45 \%$ eran hombres y $49,55 \%$, mujeres, concentrándose los mayores porcentajes de población entre los 6 y los 13 ańos (17,33\%), los 31 y los 40 (13,61\%), y los 41 y los 50 (13,82\%). Cornejo (2012) señala que El Castillo constituye uno de los tres sectores administrativos (junto con El Roble y Santo Tomás) que son producto mayormente de la erradicación de campamentos; si bien se trata de un sector más que de una población en particular, señala la autora, "donde se instalaron 31 mil personas (5.969 familias) en el período 1979-1987” (p. 187), la denominación El Castillo se superpone sobre el nombre de las poblaciones y villas. Sus límites son la avenida Batallón Maipo al norte, avenida La Prima al sur, avenida Santa Rosa al oeste y avenida La Serena-carretera Acceso Sur al oriente (Cornejo, 2012).

A continuación se examinan las condiciones de producción de El Castillo y su transformación hasta el momento presente, insertando las opiniones de informantes clave e integrantes de la muestra, a saber, jóvenes, adultos y adultos mayores con preeminencia femenina; algunos datos estadísticos, más comentarios de los autores en relación con estos aspectos. Como indica Cornejo (2012), "la erradicación concretizó en el territorio la lógica de expulsión bajo la doble determinación del Estado, el que proporciona una base legal a dichas erradicaciones -a lo que habría que agregar la represión política de la época-, y del mercado, convertido desde entonces en el principal agente en la asignación de vivienda social” (p. 187). 
figura I | Población El Castillo, comuna de La Pintana, Santiago

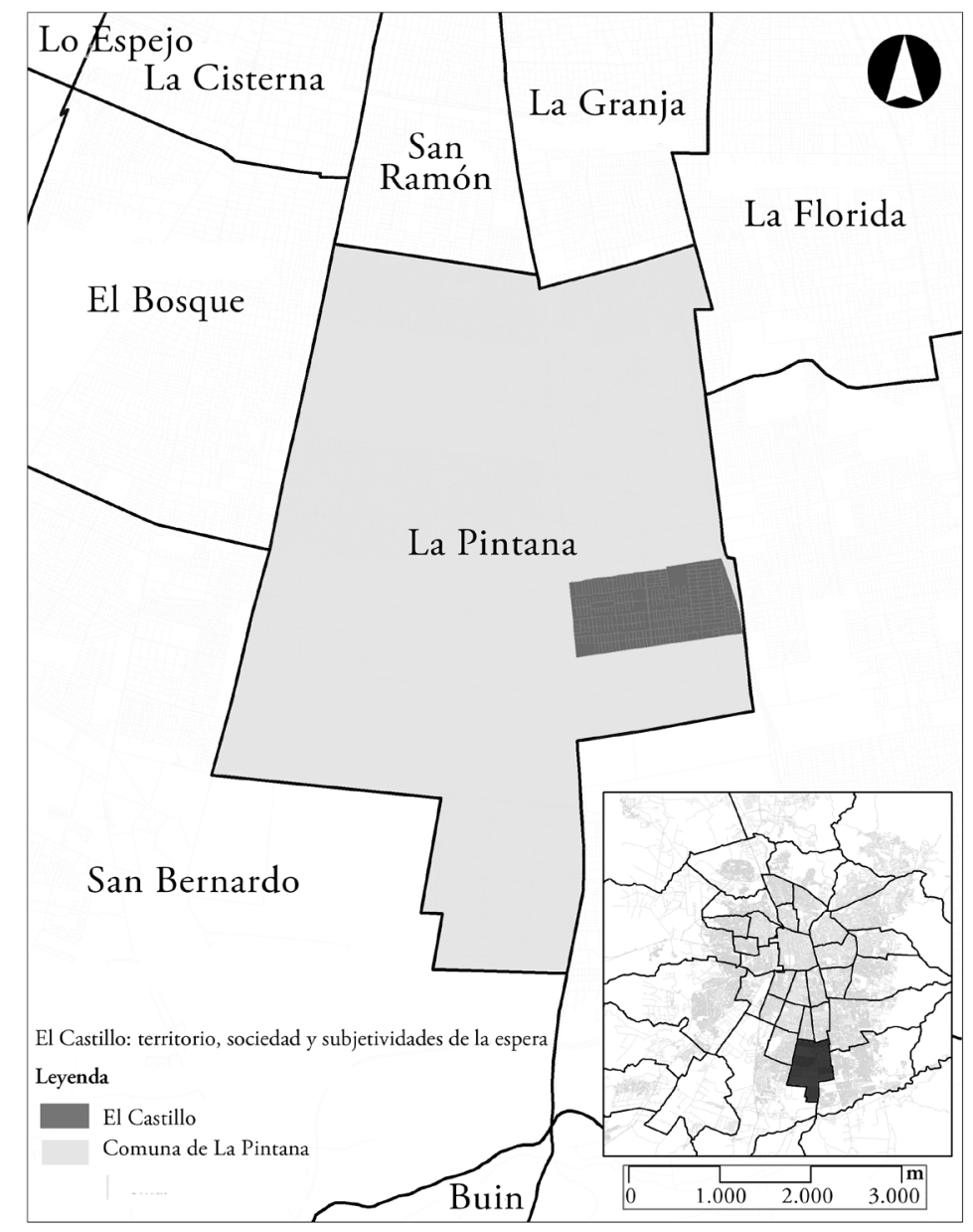

FUENTE ELABORACIÓN PROPIA A PARTIR DE INFORMACIÓN GEO ESPACIAL DEL OBSERVATORIO DE CIUDADES PUC (OCUC)

\section{Los orígenes del territorio}

El Castillo, propiedad agrícola reconocida por la gran calidad de sus terrenos, fue adquirida por el Municipio de Santiago para instalar allí población erradicada principalmente desde las zonas centro y oriente, reconocidas como espacios de alta renta y de urbanidades consolidadas (Rodríguez \& Icaza, 1993). Esta acción encontró respaldo legal en el Decreto 2552 de febrero de 1979, titulado "Programas de Viviendas Básicas o Programas de erradicación de campamentos” (De Ramón, 2000), y tuvo, entre sus fundamentos, la necesidad de proporcionar a las familias una vivienda sólida y en propiedad. Los pobladores que allí fueron radicados habían accedido a espacios centrales mediante tomas de terreno (ocupaciones ilegales) 
realizadas principalmente entre los ańos sesenta a setenta y tres. Las erradicaciones de campamentos fueron una de las medidas tomadas por la dictadura militar en el marco de las reformas neoliberales de fines de la década de los setenta, que obligó a los pobladores a dejar sus lugares de habitación e instalarse en comunas periféricas con problemas de equipamiento, infraestructura y pobreza crítica. Ello, sumado a la heterogeneidad del origen socioterritorial de sus habitantes, sin historia ni identidad compartida, y la localización segmentada respecto de las fuentes laborales y de los servicios, llevó a que, hasta el día de hoy, estos territorios hayan tenido grandes dificultades para dotarse de indicadores urbanos compatibles con estándares mínimos de calidad de vida (Álvarez \& Sánchez, 2015).

Los desplazamientos de población señalados significaron un explosivo crecimiento poblacional para la comuna, que pasó de 73.932 habitantes en 1982 a 169.640 en 1992 (I. Municipalidad de La Pintana, 2012), lo que repercutiría negativamente sobre sobre sus equipamientos y servicios: por una parte, estos no existían o rápidamente se sobresaturaron por el aumento de la población; y por otra, la localización de La Pintana hacía difícil para los pobladores allí erradicados el acceso a servicios básicos como salud y educación, en razón del aumento de las distancias a ellos en comparación con lo que ocurría en sus antiguos lugares de residencia. Para Morales y Rojas (1986), "la opción por asentarlos y mejorar sus condiciones de vida mediante la urbanización de sus sitios y construcción de una caseta sanitaria" significó "postergar indefinidamente una solución real, puesto que esta alternativa supone una alta participación de los usuarios en la expansión o autoconstrucción de su vivienda” (p. 39). Al mismo tiempo, señalan los autores, se veían disminuidas las confianzas, elemento central para el surgimiento de agrupaciones solidarias, puesto que los pobladores ya no se reconocían como parte de un conjunto social con historia común y una cierta homogeneidad, en la medida en que fueron sometidos a aceptar una convivencia con gente de distinta procedencia: "Experiencia y participación comunitarias, desarrollos desiguales de participación en las expresiones del movimiento poblacional, factores que sumados a una mínima permanencia en los nuevos entornos territoriales dificultan aún más las vías de una mayor integración” (p. 53). A la desintegración social se sumó la acentuación de la segregación urbana y la exacerbación del conflicto.

Entonces ahí, obviamente estos pobres que viven ahí, son pobres que molestan, porque le quitan la plusvalía a los terrenos (...) Entonces dentro de la lógica neoliberal hay que sacarlos; entonces los toman y los echan arriba de camiones los militares de la época de la dictadura y toman gente que estaban en esos campamentos y van y los dejan en El Castillo, digamos, y le asignan un sitio de 12x18. (Informante clave, Corporación IDECo/Instituto para el Desarrollo Comunitario)

Sí, se cumple el sueño de la casa..., pero lo que nos molestó mucho es que fue demasiado lejos. De Renca a acá, mucha distancia, porque nosotros de Renca hacia el centro... estábamos en 20 minutos. Entonces nos costaba mucho desplazarnos hacia el centro. Entonces creo que fue ese el gran problema que tuvimos nosotros al comienzo acá... (Entrevistada 2, 60 años) 
Bueno, la convivencia era muy extraña, porque era gente que no se conocía o se conocía parcialmente por grupo ¿ah?, por grupo de destino digamos. De donde vienen, esos se conocen, pero... ni tanto. Entre ellos también la vida estaba en ese minuto muy atomizada producto de los temores; entonces tú no pasabas a hablar con nadie. (Informante clave, Corporación IDECO)

La migración que hubo al sector de acá... no fue tal... Fue venir a botarlos. Ese sentimiento yo creo que queda para siempre fíjate... Entonces se quedan amarrados a un hecho que no logra generar historia, aun cuando han pasado ya varias generaciones. (Informante clave, I. Municipalidad de La Pintana)

En síntesis, se trata de un territorio creado por la voluntad de fuerzas políticas, económicas y decretos jurídicos. Un territorio "vacío", distante y desarticulado de la ciudad, en el cual sus habitantes sienten haber sido depositados como "desechos".

\section{Primera etapa. El territorio pos-erradicaciones, inicio de la transformación (1983-1987)}

En el marco de la política de vivienda social del gobierno militar, se facultó a los municipios para que construyeran viviendas económicas y casetas sanitarias, soluciones habitacionales que debían tener una superficie construida de 18 metros cuadrados y un costo inferior a $220 \mathrm{UF}^{1}$. La unidad sanitaria (baño y cocina) debía tener una superficie mínima de seis metros cuadrados y un costo máximo de 110 Uf (Ministerio de Vivienda y Urbanismo [MINvu], 1990). La mayoría de los habitantes de El Castillo, con excepción de algunos de los entrevistados que llegaron a casas "terminadas", rechazadas como opción residencial por militares a quienes les estaban destinadas ${ }^{2}$, se encontraron con un sitio demarcado con cal donde solo se había construido la unidad sanitaria, lo que implicaría procesos de autoconstrucción en vistas a la ampliación de esta unidad básica. Los primeros esfuerzos de autoridades y habitantes se orientaron entonces a dotar de materialidad este territorio vacío. Entre los desafíos a los que debieron hacer frente, estuvo la organización de la convivencia social entre personas desconocidas, con orígenes territoriales diversos y distintas trayectorias sociales y políticas, la pérdida de redes sociales y laborales y el deterioro de su situación económica y social.

Y que la gente tampoco se adaptaba, porque había mucha rencilla de los otros pobladores, que venían de otras comunas. Muchas peleas entre sí, porque habían fiestas aquí... yo me recuerdo que habían fiestas, se metía por ejemplo uno de otra comuna... se armaban tremendas peleas. (Entrevistada 2, 60 años)

Esta fase, que podríamos situar entre los años 1983 y 1987, se caracterizó por la existencia de desempleo generalizado y problemas sociales de todo tipo, lo que daría origen, según refieren informantes clave y habitantes, a un conjunto de estrategias de sobrevivencia, entre las cuales destacan la prostitución femenina y la proliferación

1 UF = unidad de fomento: unidad financiera reajustable de acuerdo con la inflación, medida según el índice de precios al consumidor o IPC. Las 220 uf equivalen a mayo de 2015 a \$5.472.705.

2 Información proporcionada por informante clave, trabajador social de la I. Municipalidad de La Pintana. 
de pequeños comercios de barrio. Recordemos que para fines de la década de los ochenta, las estadísticas señalaban que un $45,1 \%$ de la población en Chile vivía bajo la línea de la pobreza. Como una de las principales causas de esta situación estaba la crisis económica que vivió el país entre 1981 y 1986, que Barandiarán y Hernández (1999) identifican como una de las mayores del siglo pasado. Esta crisis afectó a Chile tanto en lo económico como en lo social, lo que se tradujo en una tasa de desempleo del $30 \%$ de la fuerza laboral a finales de 1983 , y en un porcentaje de alrededor de $55 \%$ de población en pobreza absoluta para ese mismo año.

\section{Segunda etapa. El advenimiento de la democracia (1999)}

Según el fundador de la Corporación IDECO ${ }^{3}$, organización con más de treinta años de presencia activa en El Castillo, el advenimiento de la democracia significó un mejoramiento general de las condiciones de urbanización y conectividad de la zona. Este hecho, si bien constituyó un avance respecto de las características fundacionales del territorio, no implicó un mejoramiento en otras esferas, tales como la instalación de fuentes laborales en el lugar o un alza en los ingresos de las familias. La comuna no contaba con los recursos financieros suficientes para hacer frente al crecimiento poblacional, profundizado con los nuevos flujos de población erradicada por la política de vivienda social de los gobiernos de la Concertación. En el marco de dicha política, se continuará desplazando población pobre hacia las periferias distantes de los centros urbanos, particularmente hacia esta comuna. Este hecho ha agudizado el carácter homogéneo del perfil social de su población y acentuado la segregación del territorio y sus habitantes. Los ingresos que genera la comuna, más los aportes del Fondo Común Municipal (FCM) ${ }^{4}$, resultan mínimos al momento de satisfacer las necesidades de mejoramiento urbano de las nuevas poblaciones, dotación de infraestructura y equipamiento comunal.

Con los gobiernos de la Concertación se urbaniza ¿ya?, se pavimentan las calles... ¡qué sé yo! Con el paso de los años, las construcciones cada vez se hacen mejores, porque empieza a haber... el trabajo, empieza a haber trabajo, la gente empieza a salir a trabajar. Para que les den trabajo dicen que viven en la casa de la abuelita, que viven en otra población y no en La Pintana. (Informante clave, Fundación IDECO)

Es largo, pero no tanto como antes. O será que con el correr del tiempo uno ya se acostumbró y no lo encuentra tan largo como en el comienzo, porque en el comienzo, cuando nos trajeron a conocer las casas, que venimos en un bus, no

El Instituto de Desarrollo Comunitario (IDECo) nació en el año 1987 con financiamiento del gobierno belga. El 21 de enero de 1991, por un decreto supremo del Ministerio de Justicia, obtuvo la calidad de corporación: entidad privada sin fines de lucro y de servicio a la comunidad, calidad jurídica que sustenta hasta la actualidad (información obtenida de la página oficial de la Corporación, http://www.corporacionideco.cl/pie_pintana.htm).

4 "El Fondo Común Municipal (FCM) corresponde a un instrumento nacional de política para el ámbito municipal, que se encuentra contemplado en la Constitución Política de la República de Chile, el cual se define como "mecanismo de redistribución solidaria de ingresos propios entre municipios". Desde los inicios de su operación, en 1980, el FCM se ha constituido en una componente relevante del sistema de financiamiento municipal, particularmente de los municipios más pobres” (Henríquez \& Fuenzalida, 2011, p. 75). 
llegamos nunca, nunca, nunca... Por Santa Rosa, Santa Rosa venía la micro, venía hacia acá y no llegábamos nunca y decíamos, ¿¿dónde están?, ¿dónde están las casas? (Entrevistada 2, 60 ańos)

Pese al aumento sostenido del presupuesto comunal entre los años 1994 y 2002, que pasó de aproximadamente seis mil millones de pesos en 1994 a ocho mil millones en 2001 (I. Municipalidad de La Pintana, 2012), los esfuerzos realizados por el Municipio resultaban insuficientes para mejorar los indicadores generales de calidad de vida de los habitantes de la comuna y atender las necesidades de una población en crecimiento. De 169.640 habitantes el año 1992, la comuna pasó a 190.085 en 2002 (Censo, 2002). El gráfico por sector de inversión (figura 2), nos permite apreciar, en un lapso de doce años, la profunda distancia entre la inversión física y la inversión institucional y en las personas. Los escasos recursos financieros de los que disponía el Municipio siguieron siendo mayoritariamente invertidos en infraestructura y equipamiento, en la perspectiva de mejorar los siempre deficitarios indicadores urbanos de la comuna. Ello en detrimento de otras áreas, como la inversión social, la inversión en seguridad o el apoyo al surgimiento y/o fortalecimiento organizacional, cuya debilidad tras su desmantelamiento durante los ańos de dictadura militar se veía acentuada por la falta de presupuesto.

FIGURA 2 Inversiones por sector (en las personas, en instituciones, física), La Pintana, 1994-2002

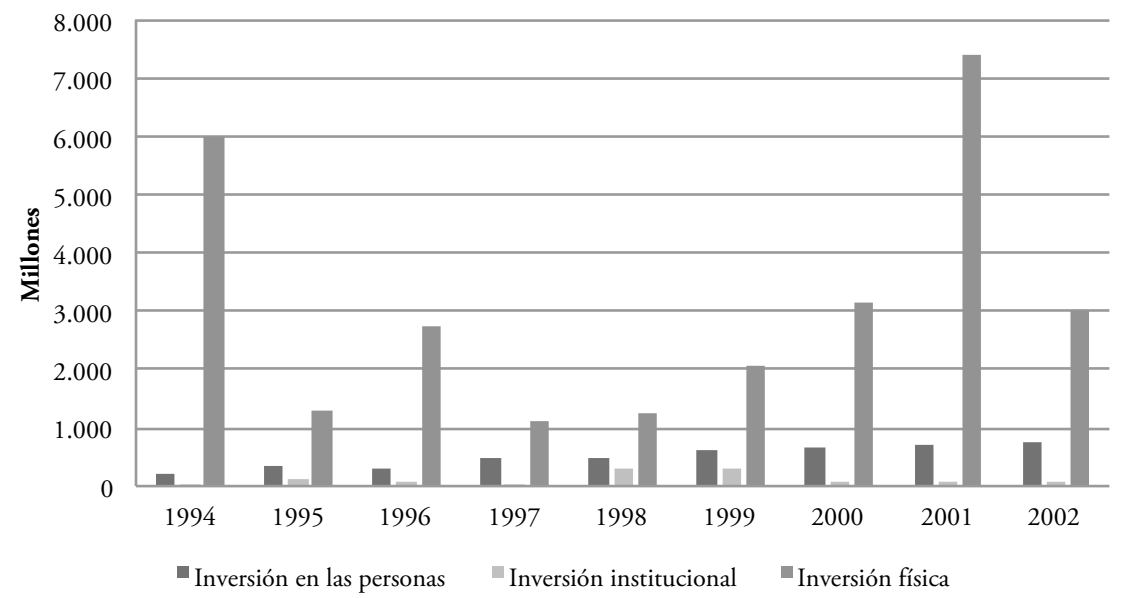

FUENTE ANÁLISIS DE INVERSIÓN COMUNAL I994-2004. SECRETARÍA COMUNAL DE PLANIFICACIÓN (SECPLA), I. MUNICIPALIDAD DE LA PINTANA, 2004

\section{Tercera etapa. El Castillo como territorio estigmatizado:}

la violencia y el tráfico de drogas

Según los reportes estadísticos y comunales proyectados del Instituto Nacional de Estadísticas (INE) (véase Biblioteca del Congreso Nacional de Chile [BCN], 2012), la población de la comuna era de 209.174 al año 2012. En tanto, se calcula que en 2015 ascendería a 212.656 habitantes. Traverso, en 2006, compara los resultados 
de un análisis socioespacial efectuado sobre El Castillo respecto de otros barrios de la comuna, para concluir que dicho sector mantiene "consecutivamente los niveles más decaídos en los factores obtenidos por la investigación de la Diferenciación del Espacio Social Intraurbano en el Gran Santiago (Schiappacasse, 1998)” (p. 142), donde se medía dimensión socioeconómica, suburbanización, estatus ocupacional nivel medio, familiar, y vivienda. Para Traverso, "esto significa que dentro de La Pintana, El Castillo se caracterizó por acumular condiciones que indicaban una fuerte vulnerabilidad social" (p. 142). Asimismo, la introducción masiva del consumo y del tráfico de drogas al sector, que habría tenido lugar principalmente en esta última década, fue marcando fuertemente las dinámicas sociales en el territorio. Todos los entrevistados, sin distinción, mencionan el peso de dicho fenómeno sobre la vida cotidiana de los habitantes de El Castillo. La mayoría lo considera el principal responsable del deterioro social del lugar.

El tráfico y el consumo de drogas han marcado fuertemente la forma y los ritmos de ocupación de espacios públicos como la calle, las plazas, los pasajes y los comercios, transformándose en una de las causas centrales de ejercicio de la violencia y el crimen entre bandas rivales que se disputan el control del territorio. Estos fenómenos han agudizado la condición estigmatizada de la población y sus habitantes, lo que, sumado a sus precarias condiciones socioeconómicas y de integración social, ha dificultado aún más las posibilidades de movilidad social de aquellos que quieren abandonar el lugar y mejorar su calidad de vida.

Muestra de lo anterior es el diagnóstico hecho por la Secretaría Comunal de Planificación (sEcPlac) de La Pintana relativo a El Castillo, según el cual un $3,38 \%$ de los hogares está en situación de pobreza crítica, 11,40\% en pobreza inercial y $9,01 \%$ en pobreza reciente, sumando un total de $23,82 \%$ hogares pobres, lo que representa el mayor porcentaje de pobreza de la comuna (Cornejo, 2012, pp. 186-187). No obstante, esta pobreza se da en el marco de una sociedad de consumo generalizado de la que los pobres participan activamente, primero como propietarios de sus viviendas, y también mediante el acceso a créditos de consumo de bienes ofrecidos por el sistema financiero y casas comerciales, con las cuales contraen importantes deudas. La pobreza crítica de los campamentos de las décadas de los sesenta y setenta, asociada a la insatisfacción de necesidades básicas, ha sido reemplazada por una pobreza de segundo orden (Tironi, 2003), caracterizada por la posesión de una vivienda de muy bajo estándar, emplazada en espacios sin cualidades urbanas y altamente segregados en términos residenciales, educativos y laborales (Kaztman, 2001; Rodríguez, 2005).

Como que todos la miran que es gente... gente drogadicta... gente alcohólica, patos malos, todo eso, siendo que todas las comunas son iguales, siendo que lo ocultan por dinero. En cambio como la comuna es pobre, todo se sabe. Salimos en las noticas, jay! disculpe... por cosas también... por robo, por asalto, por asesinato y eso a mí no me gusta... Porque cuando uno va a buscar trabajo, por ejemplo yo ando buscando trabajo: hace tiempo atrás yo tiré currículum... yo... en un supermercado y puse la comuna de La Pintana y nunca me llamaron. Yo creo que a lo mejor me discriminaron por ser de la comuna de La Pintana y eso a mí no me gusta. (Entrevistada 4, 30 años) 
La situación ha mejorado, en el sentido de que uno va a cualquier casa y encuentra un tremendo plasma, tremendo equipo de música, entonces eso es superarse...Más educación, más adquisición. Sí, en eso lo noto. (Entrevistada 2, 60 años)

Era peor la situación económica, antes era más peor. Pero se nos escapó la juventud a los viejos, a nosotros... se nos escapó, y la maldita droga se nos metió en todos lados. Antes no era tanto. La droga es incontrolable aquí en La Pintana, es incontrolable. Como tráfico, consumo y... transacciones y... de todo, hay de todo... si hay hasta, hasta... armas, armas pesadas en la población... en el sector El Castillo, armas pesadas, rifles con mira láser, pistolas con láser. Se bajaron a las tres por la tarde como si estuvieran jugando a los bandidos... y son puros mocosos. (Entrevistado 3, 65 años)

Respecto a la composición de la población de El Castillo, Traverso (2006) señala que "estarían los habitantes que han conformado su vida en la comuna a través de su instalación obligada por la dictadura militar, en tanto que en otra perspectiva estarían los habitantes que han llegado a la comuna recientemente (después de 1997), posiblemente como allegados, puesto que según el Censo 2002 solo el 10\% de la vivienda es por arriendo" (p. 90). La proyección del precenso 2011 indica una disminución de la población de 34.493 en 2002 a 30.686 en 2011, con un promedio de cinco habitantes por vivienda. Los grupos socioeconómicos $\mathrm{D}$ y E presentan un aumento de tres puntos porcentuales entre 2002 y 2011, sumando entre ambos el $84,23 \%$ de la población del sector (Centro de Inteligencia Territorial [СIT], sobre la base de INE 2011, INE 2002, CASEN 20115). A este conjunto de indicadores debemos sumar, según refiere la mayoría de nuestros informantes, el progresivo deterioro de la convivencia social, el recrudecimiento de la violencia y la agudización de los conflictos y delitos asociados al consumo y tráfico de drogas. Según el pladeco 2012-2016 de la I. Municipalidad de La Pintana (2012), "a partir de un estándar cercano a cero, los equipamientos comerciales y de servicios han tenido un importante aumento durante los últimos años; aun así, están muy lejos de ser los adecuados para la población comunal” (p. 23), situación que se reproduce con mayor profundidad en el sector analizado. Al interior de la población existe un solo consultorio, sin atención de urgencias, y la zona no cuenta con bancos ni farmacias. Asimismo, cabe consignar que La Pintana sigue mostrando tasas de desocupación superiores a las del Gran Santiago, y que esta cifra sería todavía mayor en El Castillo, según información del Municipio. Por último, de acuerdo con datos del precenso 2011, el grupo socioeconómico E habría aumentado de $27,09 \%$ (censo, 2002) a 32,63\%.

En suma, los resultados de la investigación muestran que El Castillo se ha ido configurando progresivamente como un territorio de la espera. Las diferentes etapas de transformación vividas desde su origen, y una suerte de "fijación” en la condición de espera del territorio y sus habitantes, nos hacen pensar en una verdadera "sociedad de la espera”, aspecto que profundizaremos a continuación. Territorial, de la Universidad Adolfo Ibáñez, Santiago, Chile. 


\section{El Castillo como sociedad de la espera}

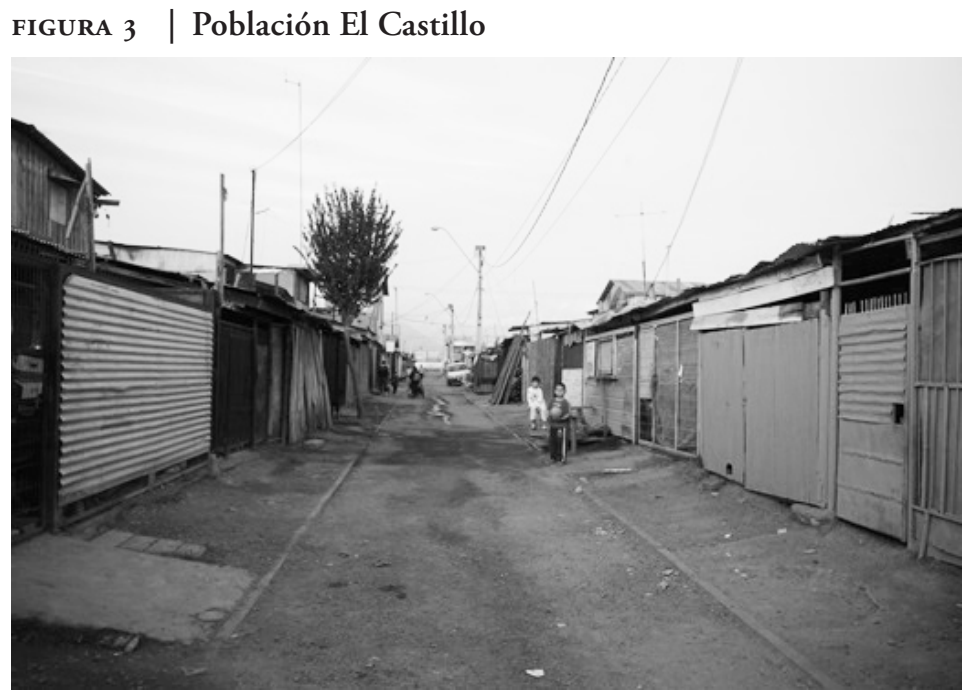

FUENTE FUNDACIÓN JUNTO AL BARRIO

Este estudio definió como rasgo esencial al momento de identificar un territorio y una sociedad de la espera, la presencia de expectativas permanentemente insatisfechas respecto a la vida y al lugar en que esta se despliega, situación en la que el territorio desempeñaría un papel fundamental. La idea de sociedad de la espera alude, entonces, a los intercambios sociales, a los aspectos intersubjetivos y simbólicos que se construyen sobre la base de la relación con un territorio de la espera y que se naturalizan como modos compartidos de comprensión de la realidad social y del espacio. Como señalan Da Costa Gomes y Musset (2015), los territorios de la espera no estarían originalmente marcados por la intencionalidad y la funcionalidad de la espera como dispositivo, régimen o proceso, sino más bien se irán transformando por la fuerza de los acontecimientos en este tipo de territorio, como ocurrió con El Castillo. Asimismo, en la espera surgen dificultades, pero también oportunidades (Vidal, Musset \& Vidal, 2011). Es lo primero que advierten nuestros entrevistados al establecer una nítida diferencia entre aquellos que escogen el comercio de drogas como mecanismo "rápido" de movilidad social, y quienes deciden estudiar y/o trabajar. Este se ve como un camino más lento pero más "seguro", aunque ello signifique enfrentar la adversidad y los obstáculos que rodean las aspiraciones de "progreso" de los pobres. Se reconoce, en estas opciones, una primera distinción en cuanto a formas de vivir la espera.

\section{Las dimensiones del ser y el estar}

Este trabajo asume la noción de territorio como espacio material concreto, pero también como espacio vivido (practicado) y percibido (representado) (Da Costa Gomes \& Musset, 2015). De ahí que los autores citados atribuyan una dimensión 
ontológica a la espera, en la medida en que dicho fenómeno determina no solo los discursos y prácticas sociales de individuos en espera (dimensión del estar), sino también su identidad y su proyección hacia el futuro (dimensión del ser). Podemos sostener que, en el caso de nuestros entrevistados, la espera se configura como dimensión fundante y transversal a sus percepciones sobre sí mismos, y sobre el territorio y la inscripción de sus prácticas sociales en él. Dado que la expectativa de un cambio se instala como elemento central en su definición de lo que "son" y de lo que hacen, su representación del futuro es ser alguien distinto del que son y esperar a que se produzcan condiciones que les permitan abandonar un territorio que no será nunca lo que debería ser.

Como anticipamos, el territorio es responsable de una primera distinción dicotómica entre sus habitantes: los que optan por mantenerse aislados del influjo negativo del entorno, manifestando un "buen obrar", alejándose de problemas y malas influencias; y quienes sucumben a los problemas sociales que caracterizan y estigmatizan negativamente el territorio, principalmente la violencia asociada a las drogas y el narcotráfico. Ambas opciones producirán distintas identidades y prácticas sociales. De este modo, los que se someten a los mecanismos de integración socialmente aceptados, buscarán demarcarse del territorio, minimizar su pertenencia para preservar una identidad social positiva, es decir, no contaminada por las características "intrínsecas" del mismo, al que definen como un lugar "contaminante". Están ahí por la fuerza del destino y de las circunstancias, porque no les dieron otra opción, porque no se pueden ir o porque renunciaron a la idea de hacerlo. Los "otros", quienes escogen caminos reñidos con la institucionalidad y la ley -traficantes, delincuentes o jóvenes en conflicto con la justicia, a quienes no se tuvo acceso en esta investigación-, aparecen en el discurso de nuestros entrevistados como individuos que, contrariamente a ellos, encarnan las características del territorio a partir de las cuales definen su identidad social: "los vatos locos" ${ }^{6}$, los "choros", los "flaites".

Paradójicamente, pareciera ser que para este perfil de habitante es el propio territorio estigmatizado el que les proporciona las armas a través de las cuales resisten el estigma y la descalificación social de la que todos se sienten objeto.

O sea... cuando yo me siento agredido como hombre del Castillo, yo lo uso... los esfuerzos de organización, los esfuerzos culturales, no, nada de eso, sino que: Sabis que más, loco, conmigo no te metái, yo soy del Castillo. (Informante clave, Fundación IDECO)

Las distintas formas de vivir la espera a las que hemos aludido, vinculadas a los tipos de inscripción del territorio en la subjetividad de los residentes, darán lugar a prácticas sociales específicas. El que escoge el camino de la transgresión, se sirve del territorio y se autoriza a ocuparlo, no tiene temor, pues es a él a quien temen $y$, en cualquier caso, está en una relación simétrica de fuerza y poder respecto de sus rivales. Esta autorización pasa por asumir el territorio como propio y relacionarse con él desde esta posición, sirviéndose del mismo como recurso para el logro 
de objetivos personales o grupales (traficar, comerciar, intimidar, consumir drogas o alcohol, asesinar). Ganter (2010), a partir de una investigación realizada en la población La Legua Emergencia, comuna de San Joaquín en Santiago, ve en ello una verdadera "narcocultura" a la que se ligan significados particulares asociados a "un estilo de vida que ofrece el máximo de beneficio al menor sacrificio posible, con un máximo de rentabilidad y placer; pero al mismo tiempo, con el riesgo y la contracara -inminente e inmanente- de la muerte o la "cana"” (p. 205). El que escoge el "buen camino" declara "no meterse" con el territorio ni con sus habitantes; pareciera ser que son solo "los otros" quienes lo usan y no ellos; se aíslan en su casa o en su pasaje para resistir el poder contaminante y el de quienes se permiten ocuparlo, lo que significa, entre otras cosas, una pérdida importante de su libertad de movimiento. La operación de apropiación del territorio que llevan a cabo los "transgresores" expulsa a los "buenos" de los espacios comunes y los obliga a un repliegue a distintas escalas: en su población, territorio más amplio por el cual se vuelve complejo y peligroso transitar, especialmente por las tardes y por la noche; $\mathrm{y}$ al interior de sus viviendas, las que se transforman en "refugios" físicos y simbólicos que los protegen del poder destructivo del entorno. En ese sentido, el propio pasaje, los vecinos cercanos, se hacen soportes de una identidad socioterritorial que se resiste a ser completamente contaminada por el peso del lugar, y que encuentra en espacios intersticiales la posibilidad de dar respiro a una identidad social deteriorada.

Yo no tengo ninguna posibilidad a irme de aquí; además que yo no tengo problemas con los vecinos, mi pasaje-gracias a Dios- es muy bueno, muy bueno mi pasaje, yo creo que uno de los más tranquilos de la población, me ha tocado. No tengo vecinos conflictivos y entonces lo mejor es no meterse con nadie tampoco, un saludo y punto. (Entrevistada 5, 45 años)

Claro, tenemos claro que no queremos eso, si hay varios pasajes que... son realmente que... hay personas realmente buenas, en ese sentido que no están con la droga, pero otros están muy perdidos [baja la voz], es otra realidad. (Entrevistada 4,30 años)

Como excepción a la situación de deterioro, hay también quienes escogen el "buen camino" y que sí se permiten ocupar la calle, permanecer apostados en las esquinas de los pasajes con fines sociales y/o recreativos. Estos son los hombres adultos cuando están sin empleo -los "buachucheros consuetudinarios", en la definición de un entrevistado; es decir, hombres que beben, comparten y se divierten "sin hacerle daño a nadie" - y los hombres viejos que logran hacerse respetar imponiendo los "restos" de autoridad que todavía le reconocen algunos jóvenes, como ellos mismos declaran.

La espera va a dar sentido no solamente al espacio, sino también a los individuos y grupos que se encuentran en él, voluntariamente o no, en una situación en que el tiempo queda sometido a los dispositivos y a las prácticas de diferentes categorías sociales o rangos de un poder más o menos visible, más o menos opresor, más o menos consciente del rol que desempeńa en la organización de la vida de los individuos en un momento determinado de sus trayectorias (Da Costa Gomes \& Musset, 2015; Kobelinsky, 2010). Vivir la espera como persona "decente" (Martínez 
\& Palacios, 1996) supone desarrollar conductas asociadas a esta cultura, principalmente estudiar, trabajar y no "meterse con nadie". Estas conductas tendrán un correlato indudable en el tipo de prácticas espaciales que podrán o no desarrollar los habitantes en el lugar y sus límites, límites que serán siempre materiales y simbólicos, en una perspectiva del territorio como espacio practicado y representado (Di Méo, 2000). Ello los orienta respecto de los lugares a los que pueden acceder y los horarios en los cuales pueden circular sin temor a ser agredidos. La opción por el "buen camino" supone, junto con resistir al poder contaminante del espacio, la voluntad de abandonar las malas prácticas cuando se ha optado por ellas en algún momento de la vida (resiliencia), lo que se reconoce como un logro puramente individual, no existiendo otra mediación entre el individuo y el sistema social que la familia.

\section{De lo general a lo particular: las generaciones de la espera}

A pesar de constituir la espera una condición transversal al conjunto de entrevistados que habrían optado por "el buen camino", su contenido varía en función de la generación de la que se trate. Da Costa Gomes y Musset (2105) señalan que el tiempo vivido se inscribe en el espacio vivido, lo que hace necesario entender cómo se establece esta relación entre el sujeto y su lugar de espera a partir de sus propias características (estatus, género, posición). Es así como, a pesar de que todos admiten que abandonarían el lugar si tuvieran las posibilidades de hacerlo, son los jóvenes quienes reconocen tener mayores chances si saben aprovechar lo que ellos mismos reconocen como "las oportunidades que da el medio". Es la generación que más confianza tiene en el logro de este propósito. La mayoría admite que hoy día en Chile existen muchas más posibilidades de "surgir" que las que tuvieron sus padres, partiendo por la de realizar estudios superiores, hasta los beneficios que otorgan los programas sociales del Estado, los progresos en materia de infraestructura y equipamiento comunal y el mejoramiento de la conectividad. En general, no experimentan "culpa" por querer abandonar el territorio, como sí es posible observar en los adultos y en los viejos. Podría decirse que la espera en el caso de este grupo etario, es esperanzada.

Para los jóvenes están cerca las cosas, hay consultorios, se puede postular a cosas, no como antes. (Entrevistada 6, 18 ańos)

Los lolos, por la misma limitación que tiene la comuna, porque la catalogan que es mala, que para acá está lo más malo, entonces... no quieren seguir cargando con ese estigma la juventud, que realmente está estudiando, que quiere superarse, quiere irse de acá. (Entrevistada 2, 60 años)

Resulta relevante señalar que la lectura que los propios jóvenes hacen de sí mismos dista de aquella que realizan adultos y adultos mayores. Si bien todos reconocen que en la actualidad existen mayores posibilidades que "en el pasado", lo que para los adultos caracteriza a los jóvenes no es precisamente la existencia de oportunidades, sino más bien "la imposibilidad", en tanto los ven como una "categoría perdida" en razón de su mayor exposición al poder destructor del consumo y del tráfico de 
drogas. Para los adultos, son los jóvenes, además, el "dato empírico" a partir del cual se estigmatiza al territorio y, de paso, a todos sus habitantes. Lo que anhelan es un cambio que les permita "salvar" a sus hijos de un entorno contaminante y contaminado, pero la precariedad de su situación económica y el peso de una vida desarrollada en la población, se lo impiden. La mayoría de las mujeres justifica el deseo de un cambio señalando que no es por ellas, sino por "el bien de sus hijos", como si no les estuviese permitido esperar para sí mismas. La espera de las mujeres adultas está fuertemente marcada por las actividades de los hijos en sus diferentes etapas de desarrollo. Los logros en el colegio, el estudio, el trabajo y el matrimonio, especialmente para las hijas mujeres, son vistos como posibilidades para salir de la condición de espera.

Que los vecinos se fueron de aquí, en ese sentido puedo decir que perdí, porque se fueron mis hijas, con ellas mis nietos. Entonces no los puedo ver constantemente a no ser que vaya allá, ella no viene para acá, mis nietos tampoco vienen para acá. (Entrevistada 2, 60 ańos)

No, igual por un lado sí me gustaría irme, sí me gustaría irme, cambiar de comuna o... no sé, de... de estilo de vida acá, por el bien de las nińas, más que nada para ellas; pero en realidad me cuesta como salir de acá....pero sí, por el otro lado me gustaría salir de acá. Sí, la mayoría quiere irse de acá. (Entrevistada 4, 30 años)

En el caso de los hombres adultos, es el empleo ocasional en el contexto de un modelo de trabajo "flexible" lo que marca la forma que adquiere la espera en el territorio y también la manera en que se relacionan con el espacio.

Esos están estancados, por ejemplo el César..., un hijo, voy a ponerles cuatro, cinco ejemplos... ese trabaja esporádicamente, sale a hacer una pega en construcción, se van a trabajar dos, tres, cuatro meses y paran un mes, dos meses y están en la esquina, su copete, su cerveza, eso no hace daño a nadie, no molestan a nadie, excepto que te pidan una moneda a uno... Yo los agarro pa'l chuleteo... ah, tú cuando trabajái no me pagái. Y ese es otro, otro tipo de gente... esos son el futuro huachuchero [se ríe], están a punto de pasar a ser huachuchero consuetudinario, ¿comprende? [se ríe]. (Entrevistado 3, 65 años)

En el caso de los adultos, podríamos hablar de una espera resignada, en tanto asumen las condiciones del entorno como invariables, no viendo las opciones que sí visualizan los jóvenes. El componente principal de la resignación se pone en evidencia en que la expectativa de cambio está en la generación futura: ellos ya no lo vivirán, pero eventualmente sus hijos podrían abandonar la espera. Es importante señalar el impacto que esta lógica tiene en la mantención del statu quo, pues el desplazamiento de la posibilidad de mejora a la generación siguiente aniquila cualquier propensión hacia el cambio social en esta generación.

Finalmente, los "viejos" asumen que se quedaron en el lugar y esperan que el tiempo "pase", mientras anhelan con nostalgia recuperar el orden y la autoridad que sí lograron imponer en el pasado, antes de la introducción masiva del consumo y del tráfico de drogas. La autoridad paterna es la condición de posibilidad para que 
los jóvenes "no se pierdan" y, por lo tanto, lo que les permite esperar como "persona decente". Si bien se reconoce la educación como el medio para que opere como mecanismo de "rescate", es necesaria la autoridad de los padres para que sea efectiva.

Junto con la evolución de la sociedad de la espera, se advierte también un cambio en el rol de la autoridad, que ya no actúa con la misma fuerza con que lo hizo en el pasado. Los entrevistados atribuyen este hecho al problema de la droga y, en menor medida, al desempleo y la falta de oportunidades, a pesar de que reconocen el peso que tiene el lugar en las opciones que hacen los jóvenes y que los hace "perderse". Los adultos mayores se sienten impotentes e incapaces de establecer normas para las generaciones más jóvenes, que los persuadan de entrar en el camino de la "cultura de la decencia” (Martínez \& Palacios, 1996). En el caso de este grupo etario, podríamos hablar de una espera nostálgica.

Mire los de los 30, los 30... esos llegaron con nosotros, llegaron de dos, tres años, entonces fueron quedando al gusto de nosotros (...) Salió una camada de cabros buenos, sanos, una camada grande de cabros sanos, y ahora en este momento tienen 27, 30 años, 35 años... y se toman su copete y se van todos juntos en su auto... o salen a cualquier parte a tomarse un copete. No es drogadicta, no es delincuente... no es nada, se busca sus pegas, sus expectativas de pegas. (Entrevistado 3, 65 ańos)

\section{FIgURA 4 Población El Castillo}

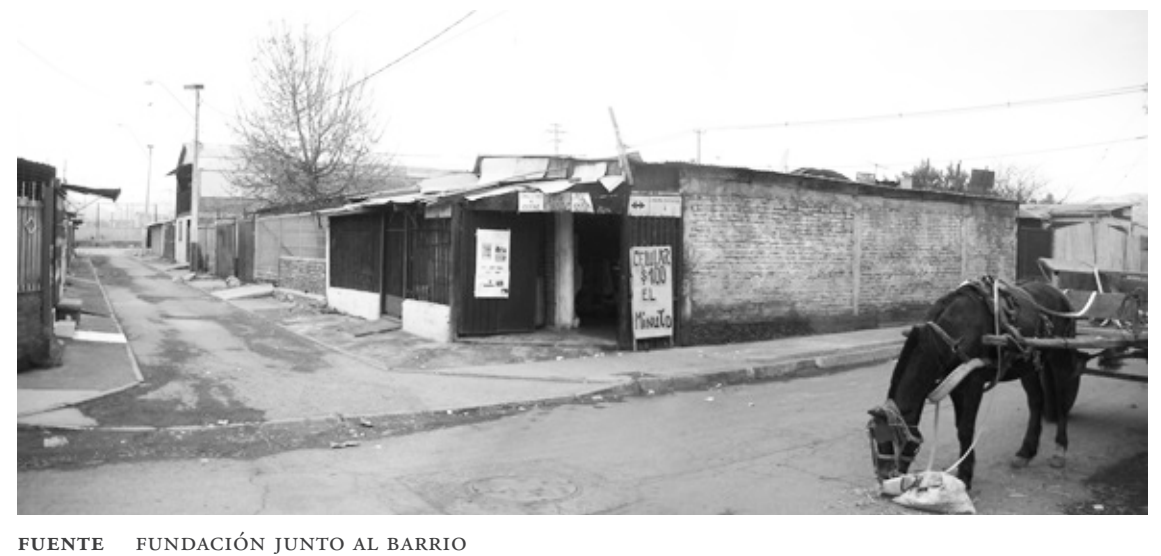

\section{Conclusiones: la eternización e invariabilidad de la espera}

La voluntad de la dictadura fue organizar institucionalmente las erradicaciones y la vida en estas nuevas comunas creadas especialmente para acoger población pobre, pero no las dotó de recursos suficientes que permitieran hacer frente al crecimiento poblacional que significó el desplazamiento masivo de familias, ni tampoco sustituir las fuentes laborales que los erradicados perdieron en los sectores donde habitaban. Este proceso de desplazamiento masivo, sin generación de condiciones materiales y sociales para garantizar el bienestar de la población erradicada, continuó durante 
los primeros gobiernos de la Concertación. A lo largo del tiempo, las características del hábitat residencial producido como resultado de esta conjunción de factores - precariedad socioeconómica generalizada y débil presencia de institucionalidad pública- ha dado lugar a estrategias de sobrevivencia de diverso tipo y a códigos de comportamiento surgidos como reacción a la exclusión social a la que la sociedad sometió a estos territorios y a sus habitantes. El escaso desarrollo que ha experimentado la comuna y la persistencia de su condición marginal y segregada respecto de los recursos y servicios urbanos, sumado a la desintegración y violencia que se vive al interior de la población, hacen que la mayoría de sus habitantes aspire a abandonar el territorio. Sin embargo, esta condición de espera estructural no se vive de manera homogénea. La génesis social del territorio, el vínculo que se establece con el Estado y la relación generacional con el espacio, producen distinciones importantes en los contenidos que adquieren los modos de la espera.

$\mathrm{Al}$ respecto, la investigación muestra que las trayectorias residenciales de los adultos mayores resultan más diversificadas que las de los otros entrevistados: ellos son quienes han vivido las migraciones campo-ciudad, los campamentos, las erradicaciones y la fase pos-erradicaciones. Asimismo, es importante subrayar que las formas de vivir la espera se transforman en estrategias para salir de dicha condición, de manera que en El Castillo la existencia humana, signada por la espera, deviene una moratoria de sí misma. No hay diferencia entre el modo de esperar y el modo de vivir. El estudio, el trabajo y la evitación de las "malas compañías" son no solo las estrategias que permiten resistir el poder contaminante del territorio y de quienes se han apropiado de él mediante la imposición de sus normas de convivencia social; son también lo que dota de contenido la esperanza de, algún día, poder abandonarlo. Habitar El Castillo como persona "decente" significa, entonces, "resistir" mientras se buscan los mecanismos que permitan dejar el lugar o aceptar, no sin nostalgia, que ya se ha hecho allí la mitad de la vida. Habitarlo como "transgresor" y, por lo tanto, vivir la espera desde esa posición, es un desafío para futuras investigaciones. Este estudio solo enuncia el problema, quedando pendiente la significación de quienes no resisten, sino más bien "se funden" con el territorio; los que habitan el espacio desde la transgresión social, los que sí lo ocupan y a quienes, además, les resulta funcional la mantención y perpetuación del estigma territorial.

Por último, resulta relevante explorar el impacto social de la espera y su inscripción en la subjetividad de quienes la viven. ¿Qué posibilidades reales de articulación tienen estos territorios urbanos, ante la funcionalidad para los individuos y el sistema social de lo que hemos llamado la "eternización e invariabilidad" de la espera? ¿Qué mecanismos psicosociales están en la base de la producción de discursos altruistas, cuya consecuencia directa es la naturalización (acaso legitimación) de la situación de exclusión y abandono social? La generación considerada bajo cualquier esquema económico como la "más productiva" - los adultos- pareciera asumir esta derrota social, construyendo una épica que consiste en pagar con sufrimiento hoy, una posible felicidad para los suyos mañana. Esta conducta introyecta e individualiza no solo la solución, sino también la injusticia, cuestión que a todos luces los habitantes de El Castillo no generaron. Ellos son las víctimas, pero no pueden verlo. 


\section{Referencias bibliográficas}

Álvarez, A. \& Sánchez, R. (2015). L’attente des pauvres dans deux villes latino-américaines: Mexico et Santiago du Chili de l'espoir à la résignation. En L. Vidal \& A. Musset (Dirs.), Les territoires de l'attente. Migrations et mobilités dans les Amériques (XIXe-XXIe Siècles) (pp. 91-109). Rennes: Presses Universitaires de Rennes (PUR).

Aragón, E. (1900). Las habitaciones para obreros. Memoria de Prueba, Universidad de Chile, Facultad de Derecho, Santiago.

Barandiarán, E. \& Hernández, L. (1999). Origins and resolution of a banking crisis: Chile 19821986 (Documento de trabajo 057). Santiago: Banco Central de Chile.

Benavides L. \& Morales E. (1982). Campamentos y poblaciones de las comunas del Gran Santiago. Una sintesis informativa (Documento de trabajo Programa Flacso 154). Santiago: Facultad Latinoamericana de Ciencias Sociales (FLACSO).

Biblioteca del Congreso Nacional de Chile (BCN). (2012). Comuna de La Pintana. Reportes estadísticos y comunales 2012 [en línea]. En http://reportescomunales.bcn.cl/2012/ index.php/La_Pintana

Cornejo, C. A (2012). Estigma territorial como forma de violencia barrial: el caso del sector El Castillo. Revista INVI, 27(76), 177-200. http://dx.doi.org/10.4067/S071883582012000300006

Da Costa Gomes, P. \& Musset, A. (2015). Des lieux d'attente aux territoires de l'attente: Une autre dimension existentielle de l'espace et du temps? En L. Vidal \& A. Musset (Dirs.), Les territoires de l'attente. Migrations et mobilités dans les Amériques (XIXe-XXIe Siècles) (pp. 61-72). Rennes: Presses Universitaires de Rennes (PUR).

De Ramón, A. (2000). Santiago de Chile (1541-1991): Historia de una sociedad urbana. Santiago: Sudamericana.

Di Méo, G. (2000). Que voulons-nous dire quand nous parlons d'espace ? En J. Levy \& M. Lussault (Dirs.), Logiques de l'espace, esprit des lieux. Géographies à Cerisy (pp. 37-48). París: Mappemonde.

Ducci, M. (1997). Chile: el lado obscuro de una política de vivienda exitosa [versión electrónica]. EURE, 23(69), 99-115. En http://www7.uc.cl/sw_educ/cyv/pdf/chile.pdf

Espinoza, V. (1988). Para una historia de los pobres de la ciudad. Santiago: Ediciones sur. Versión digitalizada en http://www.sitiosur.cl/publicacionescatalogodetalle.php?PID=2649

Ganter, R. (2010). Escenas de la vida urbana en La Legua Emergencia: narcocultura y ambivalencias identitarias. Tesis para optar al grado de Doctor en Arquitectura y Estudios Urbanos, Pontificia Universidad Católica de Chile, Facultad de Arquitectura, Diseño y Estudios Urbanos, Santiago. En http://doctoradofadeu.uc.cl/publicaciones/publicacion/ver_ tesis?id=6

Garcés, M. (2002). Tomando su sitio: el movimiento de pobladores de Santiago, 1957-1970. Santiago: LOM.

Gurovich, A. (1990) La Pintana: la ciudad interminable. Revista INVI, (9), 5:5-19. En http:// www.revistainvi.uchile.cl/index.php/INVI/article/view/96/601.

Henríquez, M. \& Fuenzalida, J. (2011). Compensando la desigualdad de ingresos locales: el Fondo Común Municipal (FCM) en Chile. Revista Iberoamericana de Estudios Municipales, 2(4), 73-104. En http://bit.ly/1W7oruN 
Ilustre Municipalidad de La Pintana. (2012). Plan de Desarrollo Comunal. PLADECO 2012-2016. Santiago: Autor. En http://www.pintana.cl/transparencia/images/OtrasInfoMunicipal/ PLADECO2012-2016.pdf

Kaztman, R. (2001). Seducidos y abandonados. El aislamiento social de los pobres urbanos. Revista CEPAL, (75), 171-189. En http://www.cepal.org/publicaciones/xml/6/19326/ Katzman.pdf

Kobelinsky, C. (2010). L'accueil des demandeurs d'asile. Une ethnographie de l'attente. París: Le Cygne.

Martínez, J. \& Palacios, M. (1996). Informe sobre la Decencia. Santiago: Ediciones sur.

Ministerio de Vivienda y Urbanismo (MINvu). (1990). Memoria 1973-1989. Santiago: Autor.

Morales E. \& Rojas S. (1986). Relocalización socio espacial de la pobreza. Politica estatal y presión popular, 1979-1985. (Documento de trabajo 280). Santiago: Facultad Latinoamericana de Ciencias Sociales (FLACSO).

Rodríguez A. \& Icaza, A.M. (1993). Procesos de expulsión de habitantes de bajos ingresos del centro de Santiago, 1981-1990. Proposiciones 22: Actores sociales y democracia. Santiago: Ediciones sur. Versión digitalizada en http://www.sitiosur.cl/r.php?id=225

Rodríguez, A \& Sugranyes, A. (2005). Mejorar el stock de vivienda social en Chile. En A. Rodríguez \& A. Sugranyes (Eds.), Los con techo. Un desafio para la política de vivienda social (pp. 201-219). Santiago: Ediciones sur.

Rodríguez, A., Sugranyes, A. \& Tironi, M. (2005). Resultados de una encuesta. En A. Rodríguez \& A. Sugranyes (Eds.), Los con techo. Un desafio para la politica de vivienda social (pp. 223-229). Santiago: Ediciones sur.

Secretaría Comunal de Planificación (secpla), Ilustre Municipalidad de la Pintana. (2004). Análisis de Inversión Comunal 1994-2004. Documento de trabajo interno.

Tironi, M. (2003). Nueva pobreza urbana. Vivienda y capital social en Santiago de Chile, $1985-$ 2001. Santiago: Universidad de Chile, Programa de Estudios Desarrollo y Sociedad (PREDES)/RIL Editores.

Traverso, G. (2006). Historia y configuración socio-espacial del sector El Castillo, comuna de La Pintana: aproximación al ghetto en el estudio de la geografia social. Memoria para optar al título de Geógrafo, Escuela de Geografía, Facultad de Arquitectura y Urbanismo, Universidad de Chile, Santiago. En http://www.repositorio.uchile.cl/ handle/2250/100904

Vidal, L. \& Musset, A. (2015a). Introduction générale. En L. Vidal \& A. Musset (Dirs.), Les territoires de l'attente. Migrations et mobilités dans les Amériques (XIXe-XXie Siècles) (pp. 7-16). Rennes: Presses Universitaires de Rennes (PUR).

Vidal, L. \& Musset, A. (Dirs.). (2015b). Les territoires de l'attente. Migrations et mobilités dans les Amériques (XIXe-XXIe Siècles). Rennes: Presses Universitaires de Rennes (PUR).

Vidal, L., Musset, A. \& Vidal, D. (2011). Sociétés, mobilités, déplacements: les territoires de l'attente. Le cas des mondes américains (d'hier à aujourd'hui). Manuscrito de los autores, publicado en Confins. Revue franco-brésilienne de géographie/Revista francobrasileira de geografia, (2011) 13. En http://hal.archives-ouvertes.fr/docs/00/75/25/49/ PDF/article_TERRIAT_pour_dA_pA_t_HAL.pdf 